\title{
III*_FAULTLESS DISAGREEMENT
}

\author{
by Max Kölbel
}

\begin{abstract}
There seem to be topics on which people can disagree without fault. For example, you and I might disagree on whether Picasso was a better artist than Matisse, without either of us being at fault. Is this a genuine possibility or just apparent? In this paper I pursue two aims: I want to provide a systematic map of available responses to this question. Simultaneously, I want to assess these responses. I start by introducing and defining the notion of a faultless disagreement. Then I present a simple argument to the conclusion that faultless disagreement is not possible. Those who accept the argument have to explain away apparent cases of faultless disagreement. Those who want to maintain the possibility of faultless disagreement must deny one of the argument's premisses. The position I want to promote belongs to the latter category and is a form of genuine relativism.
\end{abstract}

\section{I}

$\mathrm{F}$ aultless Disagreement: Definition and Examples. Most people think that there can be faultless disagreements at least on some topics, for example on matters of taste. They believe that there is a difference between disputes on objective matters of fact and disputes on non-objective matters of opinion. When two thinkers disagree on a non-objective matter of opinion it is possible that neither of them has made a mistake or is at fault. It is possible that even though they disagree, giving up the belief in question would be an improvement for neither of them. Let's call such disagreements faultless.

Candidate topics include aesthetic, culinary or moral value, probability, justification of beliefs, and many others. The examples I will be using will mostly concern matters of taste, because I believe the intuition that faultless disagreement is possible is strongest in this area. However, the range of available views on the possibility of faultless disagreement will be similar in other areas.

Let's start with a more precise definition of 'faultless disagreement':

A faultless disagreement is a situation where there is a thinker $A$, a thinker $B$, and a proposition (content of judgement) $p$, such that:

\footnotetext{
* Meeting of the Aristotelian Society, held in Senate House, University of London,
} on Monday, 10 November, 2003 at 4.15 p.m. 
(a) $A$ believes (judges) that $p$ and $B$ believes (judges) that not- $p$

(b) Neither $A$ nor $B$ has made a mistake (is at fault). ${ }^{1}$

I believe that most people have a healthy pre-theoretical intuition that there can be and are faultless disagreements in this sense. For example, imagine that Olivia believes that Matisse is better than Picasso while Felicity believes that Picasso is better. Suppose that both have had sufficient opportunity to sample the works of both artists and have given the matter enough consideration. Then it may well be that Olivia and Felicity each have exactly the view they ought to have on the question of whether Matisse is better than Picasso, and that for both of them changing their belief would constitute a mistake.

Another example: Bob believes that Grace Kelly was prettier than Mai Zetterling, while Paul believes that she wasn't. Again, both have seen the relevant films and have given ample consideration to the issue. Clearly, it seems, Bob and Paul might both be entirely without fault: there might be nothing either of them could learn that would make it recommendable for them to change their mind. Thus again: the situation is one of faultless disagreement. $^{2}$

Saying that disagreements in some area can be faultless (and perhaps sometimes are faultless), is not to say that all disagreements in that area are faultless. It is plausible to assume that some disagreements on matters of taste do involve one disputant's error. If Bob has forgotten what Mai Zetterling looked like, then this might cause him mistakenly to believe that Grace is prettier than Mai. A fresh look at a picture of Mai, or his

1. I offer 'judges' and 'content of judgement' as terminological alternatives to those who deny that the term 'belief' is properly applicable in the areas of thought under discussion.

2. Let me give a third example of a different kind: Rob believes that probably Brazil will win the World Cup and Mark believes that it is not the case that probably Brazil will win the World Cup. Given the probability function with which Rob started, and given the information he gained subsequently, his judgement that probably Brazil will win is entirely appropriate. He would be at fault if he failed to make this judgement. But the same goes for Mark's judgement that it's not the case that probably Brazil will win: it is entirely appropriate, given Mark's initial probability assignments and the information available. Subjectivists about probability tell us that this is a possible scenario (even if Rob and Mark exchange all their evidence). Thus filling in 'Rob' for ' $A$ ', 'Mark' for ' $B$ ' and 'probably Brazil will win' for ' $p$ ', gives us a true instance of (a) and (b) in the definition of 'faultless disagreement'. 
discussion with Paul, might allow Bob to expose the mistake and eliminate it. Thus, the thesis under discussion is that in some area faultless disagreements are possible, not that all disagreements in that area are faultless.

\section{II}

A Proof that No Disagreement is Faultless. The pre-theoretical intuition that faultless disagreement is possible clashes with some theoretical commitments. This section presents a simple argument in which these theoretical commitments are used to derive the conclusion that no disagreement is faultless. The rest of the paper explores whether and how this clash can be resolved, i.e. whether the argument can be blocked by dropping one of the commitments or whether instead the possibility of faultless disagreement can be credibly denied. I shall support the former view.

Here is the argument: Consider an arbitrary disagreement between $A$, who believes $p$, and $B$, who believes not- $p$. Suppose that $p$. Then what $\mathrm{B}$ believes is not true. Now suppose that not$p$. Then A believes something not true. Thus in either case, one of the disputants believes something not true. But this means that in either case, one of the disputants commits a mistake. Thus the disagreement is not faultless. Since $A, B$ and $p$ were chosen arbitrarily, it follows that no disagreement is faultless.

The argument can be more transparently represented as proceeding from two commitments. First, a commitment to instances of the equivalence schema (ES) - a commitment accepted, for example, by minimalists about truth: ${ }^{3}$

(ES) It is true that $p$ iff $p$.

Via a simple chain of inferences, this further commits one to instances of the following two schemata (I use ' $\mathrm{T}(p)$ ' as an abbreviation for 'It is true that $p$ '):

(ES1) If $p$, then not-T(not- $p$ )

(ES2) If not- $p$, then not-T $(p)$

3. This claim needs to be made more precise. Horwich, a leading minimalist, claims merely that the meaning of 'true' is constituted by our inclination to accept instances of (ES). We sometimes resist the inclination because some instances lead to inconsistency-e.g. liar instances. See Horwich 1998, p. 40-43. 
Secondly a commitment to the plausible principle that believing something that is not true constitutes a mistake:

(T) It is a mistake to believe a proposition that is not true. ${ }^{4}$ (ES) and (T) together allow the following semi-formal proof that there is no faultless disagreement:

$\begin{array}{lr}\text { A1 (1) A believes that } p . & \text { Assumption } \\ \text { (2) B believes that not- } p . & \text { Assumption } \\ \text { (3) } p & \text { Assumption } \\ \text { (4) not-T(not- } p \text { ) } & 3, \text { ES1 } \\ \text { (5) B has made a mistake. } & 2,4, \mathrm{~T} \\ \text { (6) Not- } p & \text { Assumption } \\ \text { (7) Not-T }(p) & 6, \text { ES2 } \\ \text { (8) A has made a mistake } & 1,6, \mathrm{~T} \\ \text { (9) Either A or B has made } & \\ & \text { 3-8, Constructive Dilemma }\end{array}$

On the basis of (ES), (T) and classical logic, A1 shows conclusively that if something is a disagreement (premisses (1) and (2)), then it is not faultless (conclusion (9)). There can be no faultless disagreements.

Suppose A1 is cogent, and-contrary to first impressionsestablishes that there are no faultless disagreements. Then what should we make of apparent cases of faultless disagreement, such as the situation involving Olivia and Felicity or Bob and Paul? There are two possible diagnoses (see Figure 1). Either, apparent cases of faultless disagreement are not really faultless (they don't meet condition (b)), or they are not really disagreements (they don't meet condition (a)). I shall discuss views of both sorts below.

If, however, we want to rescue the possibility of faultless disagreement, we need to reject some of the theoretical commitments that helped generate A1, i.e. either the commitment to instances of (ES) or the commitment to (T). It might appear as if replacing classical by intuitionistic logic could also help reject A1. I will discuss all these moves in due course.

4. (T) is a normative principle which claims that if it is not true that $p$, then there is a reason not to believe it. By this I mean that there is a pro tanto reason, a reason that can be outweighed by other reasons, not that all things considered there is reason not to believe $p$. For more on this difference, see Broome 2003. 


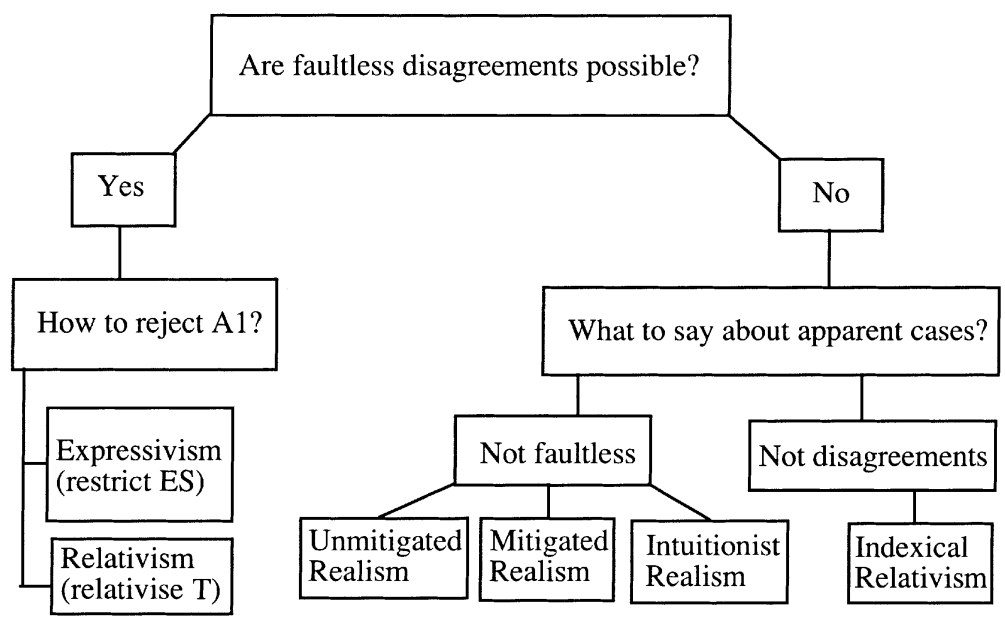

Figure 1

My plan for this paper is to concentrate in Sections III and IV on the views of those who deny the possibility of genuine faultless disagreement. They fall in two groups: realists, who say that apparent cases of faultless disagreement are not really faultless, and indexical relativists, who say that these cases are not really disagreements. Among the realists I further distinguish unmitigated realists, mitigated realists and intuitionist realists. In Sections V-VII, I shall then consider the views of those who want to rescue the possibility of faultless disagreement: expressivism and genuine relativism. For better orientation, I have added an overview which maps out all the options I will be considering (Figure 1).

The aim is to assess all the available ways of making sense of the apparent possibility of faultless disagreement.

\section{III}

Realism. Suppose we want to deny the possibility of faultless disagreement. Then we have to say something about any apparent case of faultless disagreement. There are two general options, one 
corresponding to a denial of condition (a), the other corresponding to a denial of condition (b) in the definition of faultless disagreement. In other words, we can either say it's not really a disagreement, or that it's not really faultless. I call the former 'indexical relativists', the latter 'realists'. I shall consider realism first.

Realists claim that even though it looks as if neither Bob nor Paul is at fault (when one believes Grace Kelly is prettier, the other believes she is not) this cannot be true. For a realist, proofs like A1 show conclusively that it is not the case that neither of them has made a mistake. I want to discuss three different realist positions: unmitigated realism, mitigated realism and intuitionist realism.

Unmitigated Realism. Unmitigated realists are unapologetic. They do not offer any consolation to those who found it initially plausible that there could be faultless disagreements. Thus when asked about Bob and Paul, they'll just say: well, it may be that there is no way of settling their dispute, and that it is impossible to find out who is to blame; nevertheless, one of them is wrong, because if Grace Kelly is prettier, then Paul is wrong, and if she is not, then Bob is. The fact that we cannot find anyone to blame does not show that no-one is at fault, for arguments like A1 show that someone is.

Unmitigated realism is in many ways unattractive. Most importantly, it does nothing to account for the difference between those topics on which we are inclined to say that faultless disagreement is possible and those where we are not. We clearly accord different status to disagreements in different areas: when we disagree on how many people are in the room we assume that this shows that one disputant at least is in error, and that's why further discussion or investigation is called for (if the matter is of sufficient interest). However, when we disagree on whether sardines are tasty, we make no analogous assumption. In this case we don't assume that the fact we are disagreeing indicates that one of us is mistaken and that therefore further discussion or investigation is called for. We make this distinction in a systematic way that is guided by considerations about the differences between subject matters, as is reflected in the saying that there is no disputing about matters of taste. What the difference consists in is a matter worth debating. However, it seems to 
me to be an undeniable fact that we make some such difference in status and that this is a practice worth preserving. Thus, a theory that does not at least provide some account of the difference is clearly unattractive.

Mitigated Realism. The position I want to call 'mitigated realism' addresses this point. Mitigated realists continue to insist that every disagreement involves a fault in the sense that one party believes something untrue, but they add that there is nevertheless a different sense in which disagreements can be faultless. Even though Bob and Paul have each taken into account a sufficient proportion of the relevant evidence, and they have processed that evidence without any mistake, they still arrive at contradictory views concerning whether Grace Kelly is prettier. Thus neither of them has made any mistake that he should have avoided. They both did exactly what they should have done. One of them, however, has a false belief and could in that sense have improved his situation by giving up that belief. ${ }^{5}$ This position accepts the conclusion of proof $\mathrm{A} 1$, but it nevertheless defines a new and different sense in which disagreements can be, lets say, cognitively faultless. Crispin Wright in his book Truth and Objectivity in effect defends such a position. He allows that in some areas of discourse disagreement without cognitive shortcoming is possible. $^{6}$

This represents a substantial improvement over unmitigated realism. Saying that there are areas where we assume that disagreements may be cognitively faultless, while there are other areas where we assume that they cannot, seems to take care of the intuitive difference in status we make between disagreements in different areas. But there is a new problem. Even mitigated realists claim that in apparent cases of faultless disagreement, some mistake is made, a mistake that we have no way of detecting, because both disputants are cognitively faultless. This means that both have followed the correct methods for arriving

5. This would, in another sense, have made his epistemic situation worse: he would have failed to believe something his evidence gives him reason to believe.

6. Wright wants to make room for areas of discourse that fail to exert what he calls 'Cognitive Command', i.e. areas where, roughly, it is not a priori that disagreements involve cognitive shortcoming. In his 1992 the response to arguments like A1 is to insist that believing something not true may not amount to cognitive shortcoming. His response is different in his 2001 and 2002-see below. 
at a view on the matter, methods that are in accordance with the concepts involved in the beliefs in question. Ignorance of relevant evidence or faulty reasoning is not an issue. Nevertheless one of them believes something false. This is puzzling. It means that the truth-values of these beliefs are somehow settled not only independently of, but also in conflict with, the methods of flawless thinkers.

It may be worth clarifying that the objection just raised does not depend on verificationism of any sort. Verificationism is the view that there are no facts that are (in principle) undetectable by us. The above objection involves quite a different, independent claim: that there can be no facts about which flawless method misleads us. For cognitively faultless disagreement is, on the current view, said to involve someone who is competent with the concepts involved in his judgement, fully informed and performing any processing of information flawlessly, but still acquires a belief that is false. In what sense, then, is this method flawless? How can a flawless thinker arrive at a belief that is in fact false? If there was no relevant evidence our allegedly flawless thinker has ignored, then surely at least he or she should have been more cautious and stopped short of forming any views on the matter.

Verificationists will, however, have a different problem with mitigated realism. Suppose we are committed to the view that truth is epistemically constrained and therefore accept instances of the following schema:

(EC) If it is true that $p$, then it is feasible to know that $p .^{7}$

Then we can run a new version of A1 that proves that disagreements always involve cognitive shortcoming of some sort. Suppose $A$ believes that $p$ and $B$ believes that not- $p$. Now suppose $p$. Then $\mathrm{B}$ is guilty of a cognitive mistake because $B$ believes the negation of something which it is feasible to know. Now suppose that not- $p$. Then it is feasible to know the negation of something $A$ believes. So in that case $A$ is making some cognitive mistake. In either case one of the two is guilty of a cognitive mistake.

Intuitionist Realism. The above problem has led Crispin Wright $(2001,2002)$ to propose a third variety of realism about apparent

7. Wright is committed to (EC), see his 1992, p. 41 and 2001, p. 59, 2002, p. 108. 
cases of faultless disagreement. ${ }^{8}$ I shall call this variety 'intuitionist realism'. Wright observes that the above proof of the impossibility of faultless disagreement, A1, relies on the inference rule of constructive dilemma. This rule is not acceptable to intuitionists. As Wright notes, however, there is a version of A1 that proves a similar conclusion without relying on constructive dilemma, instead using reductio ad absurdum (RAA):

A2 (1) A believes that $p$
(2) B believes that not- $p$
(3) Neither A nor B has made a mistake)
(4) $p$
(5) not-T(not- $p$ )
(6) B has made a mistake
(7) Not- $p$
(8) Not-T $(p)$
(9) A has made a mistake
(10) Not-(neither A nor B has made

Assumption Assumption

Assumption Assumption 4, ES1
$2,5, \mathrm{~T}$
$4,6,3, \mathrm{RAA}$
$7, \mathrm{ES} 2$
$1,8, \mathrm{~T}$ 3, 9, RAA

One double negation is the only difference between A2's conclusion and A1's original conclusion, i.e. the conclusion that either A or B has made a mistake. Intuitionists like Wright will refuse to eliminate this double negation. What are we to make of the difference? Clearly, A2 still forces a denial of the possibility of faultless disagreement: it proves that if two thinkers disagree then it is not the case that neither of them is at fault. An intuitionist can combine this denial of faultlessness with a refusal to say that one of the two has made a mistake. There is a subtle, but according to Wright important, difference.

Wright seems to think that this entitles him to say, of an apparent case of faultless disagreement, that 'there need be nothing about which either disputant is mistaken' (2001, p. 53). But he can consistently think so only if this does not entail 'It is possible that neither disputant is mistaken.' He also seems to believe that we can somehow ameliorate the fact that we have to deny the faultlessness of every dispute by selectively refusing to

8. The objection in this form was thought up by Shapiro and Taschek 1996. Another criticism that has been made repeatedly was that the 1992 account requires an independent account of cognitiveness, see Williamson 1994, p. 140, and Sainsbury 1996, p. 902. 
affirm of some disputes that they involve a fault. For example, when Bob and Paul disagree whether Grace Kelly is prettier, it is not the case that neither of them has made a mistake. So it is not a faultless disagreement. However, in order to do justice to our - as it turns out false-intuition that neither of them is mistaken, we can refuse to assert that one of them is mistaken. ${ }^{9}$ It is unclear to me how this ameliorates the situation. Faced with the unmitigated realist's affirmation that one of them is mistaken, the best he can do is remain silent. The intuitionist is not able to deny the claim that one of them is mistaken. Worse: intuitionist realism does not even allow us to state that there is some sense in which the disputants in question are blameless. I conclude that intuitionist realism is in a worse position than mitigated realism to account for our intuition that some disagreements are faultless.

\section{IV}

Indexical Relativism. On the right hand side of my diagram (see Figure 1 in Section II), only one position remains: indexical relativism. The positions considered so far all say that apparent cases of faultless disagreement are not really faultless. Indexical relativists, by contrast, say that they are not really disagreements, at least not in the sense required by clause (b) of my definition of 'faultless disagreement'.

Indexical relativists hold that apparent cases of faultless disagreement have been misdescribed. More precisely, the contents of the beliefs of the allegedly disagreeing parties have been misdescribed. Let's consider one particular indexical relativist proposal

9. Wright tries to make this strategy more attractive by embedding it into a general theory of what he calls 'quandaries'. A proposition $p$ is a quandary for us just if

We do not know what to say about $p$, do not know how we might find out, and can produce no reason for thinking that there is a way of finding out or even that finding out is metaphysically possible. (2001, pp. 77-8).

A paradigm case of a quandary would be, for example, Goldbach's Conjecture, and other cases include propositions concerning borderline cases of vague properties. It is not clear to me how this theory is supposed to illuminate typical cases of apparent faultless disagreement of the type I have been considering. Clearly, the proposition about which the disputants disagree is not a quandary. Consider a dispute about whether sardines are tasty: we have no problem whatsoever in making up our mind about this. But if the proposition that sardines are tasty is not a quandary, how can it be a quandary that A or B has made a mistake about whether sardines are tasty? 
regarding matters of taste, according to which judgements of taste are always judgements about one's own preferences. We may think that Olivia believes Matisse is better than Picasso and Felicity believes that he is not. However, this characterisation of the contents of Olivia's and Felicity's beliefs is at best misleadingly incomplete. It would be more accurate to say that Olivia believes that she prefers Matisse, while Felicity believes that she does not.

'Indexical Relativism' is an apt name for this view because it also involves a semantic thesis. ${ }^{10}$ Someone uttering the sentence 'Matisse is better than Picasso' thereby asserts the same proposition they would have asserted had they uttered the following sentence instead: 'I prefer Matisse to Picasso.' ${ }^{\text {'1 }}$ The sentence offered as a propositional equivalent contains an indexical reference to the speaker.

All versions of indexical relativism will involve such a claim: a claim to the effect that sentences of a certain sort, which may not be overtly indexical, are nevertheless propositionally equivalent to a related indexical sentence. Thus we can imagine a whole range of other sentences that might be proposed to be propositionally equivalent to 'Matisse is better than Picasso:'

(IR1) I prefer Matisse to Picasso.

(IR2) My standard of taste rates Matisse above Picasso.

(IR3) The standard of taste of my group rates Matisse above Picasso.

(IR4) The standard of taste of the experts recognized in my society rates Matisse above Picasso.

Each of these proposals will give rise to a distinct form of indexical relativism about matters aesthetic.

Indexical relativists can effortlessly maintain that no-one is at fault in apparent cases of faultless disagreement. But they do so at the cost of distorting the topic of the beliefs and assertions involved. I believe it to be a distinct disadvantage of indexical

10. The term is borrowed from Crispin Wright.

11. The view I am discussing does not explicitly involve the thesis that the two sentences mean the same. It explicitly involves only the thesis that uttering the sentences results in expression, and assertion, of the same proposition. I make this distinction because James Dreier, a proponent of an indexical relativist view of moral judgement, attaches great to weight to it in his 1999, p. 567. 
relativism that it has to deny that there is any difference between believing that Matisse is better and believing that one prefers him. ${ }^{12}$ We make this difference pre-theoretically and denying us the right to make it should count as a distinct disadvantage.

Let me try to make this disadvantage more vivid by applying the view to a particular case. Imagine I believe on Monday that Matisse is better, and I also believe that I prefer Matisse. Call the first belief B1, the second B2. On Tuesday, I do some research, look at some paintings etc. On Wednesday I no longer believe that Matisse is better. I now think that my belief $\mathrm{B} 1$ is false, because Matisse isn't better; while my belief B2 is true, because I did then prefer Matisse. The indexical relativist we are considering must say that my retrospective assessment is wrong: I ought not to think that B1 is false and B2 true. Rather, I should say that $\mathrm{B} 1$ and $\mathrm{B} 2$ were both true. I think this is unsatisfactory. We should be able to say that my retrospective assessment is correct. The difference between believing that Matisse is better and believing that one prefers Matisse is an important difference that is worth preserving.

It is easy to see that all versions of indexical relativism face analogous problems. I therefore conclude that indexical relativism is also an unattractive way of resolving the conflict between the proof $\mathrm{A} 1$ and our intuition that faultless disagreement is possible.

\section{V}

Expressivism: Restricting (ES) and (T). Those who want to maintain the possibility of faultless disagreement need to reject the assumptions that allowed us to generate the proof A1 in Section II above. We have already seen that adopting intuitionistic logic (rejecting the inference form of constructive dilemma) does not prevent the conclusion that disagreements are never faultless. Thus we now need to consider the possibility of dropping either the commitment to instances of (ES) or that to (T).

12. Or, on the alternative indexical relativist views mentioned above: they have to deny the difference between the belief that Matisse is better and the belief that one's standard of taste rates him higher, or the belief that the standard of taste of my group rates him higher, etc. 
Expressivists might want to reject A1 on the grounds that it wrongly presupposes that matters about which we might disagree faultlessly are within the range of applicability of 'true'. The judgement that Matisse is better, say, is just a sentiment or attitude and therefore not a candidate for truth or falsehood. The sentence 'Matisse is better' does not express a truth-apt proposition, but rather some non-truth-apt content of judgement. Thus, they might want to restrict the range of instances of (ES) to which they regard themselves as committed. Thus 'It is true that Matisse is better iff Matisse is better' is not a legitimate instance of (ES). Moreover, application of (T) in A1 wrongly presupposes that all judgements are truth-evaluable.

However, I do not think that expressivism helps us escape from the conclusion that there can be no faultless disagreement. Expressivists face a dilemma: either they are Ayer-style expressivists and do not believe that there can be anything like proper disagreement on evaluative matters. Or they are Blackburn-style expressivists, in which case a version of A1 can be re-constructed in terms they cannot object to. I shall discuss each horn of the dilemma in turn.

First, consider Ayer-style expressivism, according to which a statement like 'Grace Kelly is prettier' is not even in a minimal sense cognitive: it just expresses a preference, but there are no logical relationships into which the statement, or the sentiments expressed by it, could enter. On this view, when Bob judges that Grace Kelly is prettier, and Paul judges that she is not, they are not disagreeing - in Ayer's words: 'It is impossible to dispute about questions of value' (1946, p. 110). Apparent cases of faultless disagreement are not really cases of disagreement. Occasionally we might appear to be disputing on a question of value, however the appearance is deceptive: the dispute, if there is one, is really about a related factual question, and this dispute is not faultless. Thus an Ayer-style expressivist has no room for faultless disagreement. ${ }^{13}$

Secondly, let's consider more sophisticated expressivists, like Blackburn who are prepared to say that the judgements in question do enter into logical relations, even though they are not

13. Strictly speaking, Ayer-style expressivism could now re-deploy on the right hand side of the diagram. Nothing I have said prevents that. 
strictly speaking truth-evaluable. Typically, such expressivists attempt to reconstruct something at least syntactically like standard logic for the judgements about which they are expressivists (compare Blackburn 1984, Ch. 6 and Blackburn 1988-this attempt is absent from Blackburn 1998). This will enable them to claim credibly that there can be disagreements in the area under discussion.

However, any standard logic (including even intuitionistic logic) will also enable a reconstruction of A1 without any assumptions about the range of applicability of the truth-predicate. (T) need not be regarded as a normative principle regarding truth. The notion of truth merely allows a particularly convenient formulation of this normative principle. Instead of committing us to $(\mathrm{T})$ we could strip away its truth-related content and commit ourselves instead to instances of the following schema:

(T*) If not- $p$, then it is a mistake to believe that $p$.

Surely, the sophisticated expressivist will want to accept this principle. We can then run a new, truthless version of A1:
A3 (1) A judges that $p$
(2) B judges that not- $p$
Assumption
(3) $p$
Assumption
(4) not-not- $p$
Assumption
(5) B has made a mistake
$2,4,\left(\mathrm{~T}^{*}\right)$
(6) Not- $p$
(7) A has made a mistake
Assumption
(8) Either A or B has made a mistake
$1,6,\left(\mathrm{~T}^{*}\right)$
$3-7, \mathrm{CD}$

It is easy to see that intuitionistic expressivists won't escape either, because there is a truth-less version of the intuitionistic argument A2 lurking.

\section{VI}

Reconsidering $(T)$. It is hard to deny that it is a mistake to believe something not true, which is what (T) states. Not because this is some fundamental principle regarding truth (I have already pointed out above that the normative content of $(\mathrm{T})$ is contained in $\left(\mathrm{T}^{*}\right)$, the principle that it's wrong to believe a proposition $p$, 
if not- $p$ ) but rather because (T) is a fundamental principle governing belief.

Huw Price, in the context of two articles about the normativity of truth (1998 and 2002) discusses a close relative of (T) concerning assertion:

(A) It is a mistake to assert something not true.

He says that it is because of (A) that we treat disagreements as indicative of some mistake on the part of one of the disputants in a verbal dispute. He thus seems to agree that a principle like (A) prevents the existence of faultless disagreement, i.e. a verbal exchange in which one person asserts that $p$, another person asserts that not- $p$ where neither of them has committed a mistake.

Price argues that a linguistic community whose institution of assertion was not governed by (A) would be seriously deprived. He calls assertion of this kind 'Merely Opinionated Assertion' (MOA). In a language community where assertion is MOA, disagreement would fail to motivate argument and discussion. When one speaker asserts that $p$ and another asserts that not- $p$, there would not need to be a reason to assume that one of them must be wrong. However, discussion and argument have an important cognitive function. When arguing about a contentious proposition, speakers exchange the reasons they have for their views. One speaker may learn important considerations and facts from another, or one speaker may help another detect some mistake. Discussion thus helps speakers pool their cognitive resources. But the best way to motivate discussion is a normative principle like (A), according to which disagreement indicates that one of the disagreeing parties is in error. Thus, any speech community whose institution of assertion is not governed by (A) would soon introduce (A). MOA would quickly go extinct.

I share Price's view that discussion and argument is an essential and valuable aspect of linguistic communication. I also share his view that it is some a priori rule like $(\mathrm{A}),(\mathrm{T})$ or $\left(\mathrm{T}^{*}\right)$ which typically motivates discussion. It's because we assume that only one of two conflicting beliefs can be correct and that one of them must be mistaken that we think arguing about it makes sense. However, Price's considerations do not show that assertion can never legitimately be 'merely opinionated'. I want to argue that 
the best system of communication is neither one where all disagreements are potentially faultless nor one where all disagreements are presumed to involve error. Rather the most sensible system of communication is one where some areas are deemed to permit faultless disagreements and others are not.

Here is a brief sketch of this view. Beliefs, and the concepts constituting the contents of beliefs, are governed by many a priori constraints and rules. ${ }^{14}$ These rules are $a$ priori because we learn them as and when we learn how to acquire beliefs and how to reason with them. Since we learn these things through learning language - it is hard to separate the two processes - they are largely in tandem with a priori rules governing language. The $a$ priori principles a competent thinker/speaker knows crucially concern the conditions under which one is justified and/or obliged to hold a given belief. Thus there will be rules governing which perceptual inputs justify which beliefs, which beliefs justify which other beliefs, which course of action is motivated by which beliefs etc. Sometimes, we learn these rules through being explicitly told (e.g. when looking up an unknown word in a dictionary). But often we pick them up through example in individual cases. The learner ventures to express a belief, and the teacher either reinforces or corrects the attempt. Or alternatively, the teacher leads by example.

Sometimes the a priori constraints governing beliefs involve the rule that different thinkers ought to agree, sometimes they don't. That is, with some contents of belief (propositions) there is a presumption that if one thinker correctly believes them, then no other speaker can correctly believe the negation of that content. For example, when I correctly believe that there are 25 chairs in this room then you can't correctly believe that there aren't 25 chairs in this room. Arguably, this is an a priori rule every competent thinker knows. With other contents, there is room for legitimate disagreement, and we learn that this is so when learning how to speak and think. For example, usually teachers will allow that learners believe that chocolate ice cream is delicious even if they themselves believe it isn't. This doesn't

14. This a priori knowledge need not be explicit knowledge. It will be largely implicit. Moreover, it is sometimes perhaps more appropriate to speak of abilities rather than knowledge, as it is doubtful whether all this a priori knowledge has propositional form. 
mean that belief in such discretionary contents is entirely unconstrained. There will be other constraints which the learner can violate and be criticised for. For example, if a learner claims to believe that chocolate ice cream is delicious, but nevertheless denies that he or she is motivated to eat chocolate ice cream (under certain normal conditions), then he or she will be criticised for not having mastered certain a priori rules governing the concept of deliciousness (or perhaps governing the extension of 'chocolate ice cream').

It is no coincidence that there should be discretionary contents of belief. Sometimes there are a priori constraints that tie a belief to certain features of its possessor. If these features then differ from thinker to thinker, then the content better be of the discretionary sort. ${ }^{15}$ The above example is a case in point: if the belief that sardines are tasty has certain a priori practical consequences the appropriateness of which depends on thinkers' individual constitution. It would thus be crazy to require that different thinkers must always agree on this on pain of one of them being in error. ${ }^{16}$

\section{VII}

How to Make Room for Faultless Disagreement. If these considerations are correct, it would be crazy to accept $(\mathrm{T})$ or $\left(\mathrm{T}^{*}\right)$ as they stand. Let us therefore briefly consider how (T) could be modified in order to avoid A1's conclusion.

One simple suggestion would be to restrict the range of $(\mathrm{T})$ to those areas where we are happy to rule out faultless disagreement. Suppose we wanted to rule out faultless disagreement in

15. Some might say that these so-called discretionary belief contents aren't really belief contents (as do Ayer-style expressivists). But there are good reasons to treat these contents as uniform with contents that are uncontroversially contents of belief: they bear the same logical relations to one another and to other contents and the reasoning patterns in the areas in question are not fundamentally different.

16. Of course these rules, even though they are a priori, could have been different, or could become different. If we think that words and concepts are partly individuated by the a priori rules that govern them then considering a situation in which the rules are different is considering a situation in which we have different words and concepts. Sometimes there is controversy on what the rules are-an example is the debate about internalism in meta-ethics. Such controversies can be seen as controversies on what our concepts are. Sometimes there just is uncertainty on what the rules are (and perhaps we are just negotiating what they are to be). This shouldn't be surprising given that these rules are human institutions. 
all areas except discretionary discourse (see Section VI above on discretionary contents of belief). Then we could revise (T) thus:

$\left(\mathrm{T}^{* *}\right)$ It is a mistake to believe a non-discretionary proposition that is not true.

$\left(\mathrm{T}^{* *}\right)$ expresses a normative principle regarding all non-discretionary beliefs. It tells us, one might say, that non-discretionary belief aims at truth. But what, then, is the aim of belief in discretionary propositions? Is it not a mistake to believe that $p$ when $p$ is not true if $p$ is from the discretionary range? Surely, we don't want to allow as a possibility that sometimes it is not a mistake to believe that sardines are tasty when they are not tasty.

Clearly each individual thinker aims to avoid incorrectly believing even discretionary propositions. But it may be correct for one person to believe a given discretionary proposition, while it is not correct for another person to believe the same discretionary proposition. Thus it seems wrong to say that truth is not a norm for belief in the discretionary area. There clearly are norms governing these beliefs, and it seems possible to articulate this in terms of truth, as long as this allows that the same proposition can be evaluated differently from different points of evaluation, where different points of evaluation may be appropriate for different people. Let's call the point of evaluation appropriate for a person that person's 'perspective' (where a perspective is a function that assigns truth-values to propositions). Then we could introduce a relativised version of $(\mathrm{T})$ :

$\left(\mathrm{T}^{* * *}\right)$ It is a mistake to believe a discretionary proposition that is not true as evaluated from one's own perspective.

Clearly, ( $\left.\mathrm{T}^{* * *}\right)$ would permit faultless disagreements as long as different people sometimes have distinct perspectives.

For reasons of uniformity, I prefer to relativise truth of all propositions across the board, i.e. to say that the truth of every proposition is relative to a perspective, so that we can use one unified relativised version of $(\mathrm{T})$ :

(TR) It is a mistake to believe a proposition that is not true in one's own perspective. 
This simplification does not prevent us from continuing to say that faultless disagreement is impossible in some (the non-discretionary, objective) areas. Whether, and in which areas, faultless disagreement can be ruled out will depend on the relation of perspective possession.

Why and how do thinkers get to possess perspectives? Since we have stipulated a connection between the notion of mistake and the relation of perspective possession in (TR), an answer will need to be in accordance with the a priori rules governing correct and mistaken belief-formation. For example, it may be that generally a belief to the effect that $X$ is tasty is mistaken if $X$ tends to cause a certain emotional response $D$ in the believer. This would constrain the relation of perspective possession: it would rule out, for example, that someone who exhibits response $D$ to anchovies possess a perspective which evaluates as correct the proposition that anchovies are tasty. Thus, the relation of perspective-possession is constrained - in ways similar to the one suggested-by a priori rules concerning the correct methods of belief-formation.

In order to clarify the relativisation involved in this form of relativism it will be useful to compare it to some more familiar kinds of relativisation. Consider the relativity of the content expressed by an indexical sentence to the context of utterance, the relativity of the truth-values of propositions to possible worlds, ${ }^{17}$ and the relativity to times of the truth-value of Priorstyle tensed propositions. ${ }^{18}$ My proposal is most akin to the last of these three. The first kind of relativisation is what the indexical relativist employed: when Bob says 'Grace Kelly is prettier' he expresses a proposition distinct from the proposition whose negation Paul expresses when he utters 'Grace Kelly is not prettier.' My proposal involves not just relativity at the level of sentences. Rather, the same proposition (content of belief, assertion etc.) is true in some perspectives, and not in others. This form of relativity is not eliminated by placing a sentence in a context of utterance.

17. These are the two dimensions of evaluation involved in Stalnaker's and Kaplan's two-dimensional semantic framework, see e.g. Kaplan 1977 and Stalnaker 1978.

18. See Prior 1962. MacFarlane 2003 also argues for a semantics of tensed sentences according to which utterances of tensed sentences vary in truth-value according to the time at which they are evaluated. MacFarlane, though, stops short of introducing propositions with relative truth-values. 
The relativism I am considering does not claim that the content expressed varies with context of utterance, but rather that the truth-value of the content itself is relative. In this respect, my proposal is similar to the world relativity of truth proposed in possible world semantics: the same proposition (content) can be evaluated differently in different possible worlds. The same goes for perspectives: the same proposition can be evaluated differently in different perspectives. However, there is also an important dissimilarity. Any two people communicating with each other will always be at the same possible world. ${ }^{19}$ By contrast, two communicators can possess different perspectives. This is the crucial difference between perspectives and worlds, for this makes possible that they believe contradictory propositions without committing any mistake, i.e. without believing something not true in their own perspective.

The purpose of this brief sketch was to show that there is a serious position on the left hand side of the diagram. I hope that, together with the problems raised for all other positions discussed, this provides some support for relativism. ${ }^{20}$

\section{Department of Philosophy \\ University of Birmingham \\ Edgbaston \\ Birmingham B15 2TT}

\section{REFERENCES}

Ayer, A.J. 1946: Language, Truth and Logic, 2nd edition, London: Victor Gollancz.

Blackburn, Simon 1984: Spreading the Word, Oxford: Clarendon Press.

Blackburn, Simon 1988: 'Attitudes and Contents', Ethics 98, pp. 501-17.

Blackburn, Simon 1998: Ruling Passions, Oxford: Oxford University Press.

Broome, John 2003: 'Reasons', in R. Jay Wallace, Michael Smith, Samuel Scheffler, and Philip Pettit (eds.), Reason and Value: Essays on the Moral Philosophy of Joseph Raz, Oxford: Oxford University Press.

Dreier, James, 1999: 'Transforming Expressivism', Nous 33, pp. 558-72.

19. Because they are causally related and there are no causal relations across worlds-compare Lewis 1986, p. 3.

20. I would like to thank the following for discussion and comments on various points: Darragh Byrne, Bob Hale, Carrie Jenkins, Penelope Mackie, Andrew McGonigal, Alex Miller, Harold Noonan, Mark Sainsbury, Nicholas Shackel, Alessandra Tanesini and audiences at Cardiff University and at the 2002 Joint Session in Glasgow. 
Horwich, Paul 1998: Truth, 2nd edition, Oxford: Oxford University Press.

Kaplan, David 1977: 'Demonstratives', in Almog and Perry (eds.), Themes from Kaplan, Oxford: OUP 1989.

Price, Huw 1998: 'Three Norms of Assertibility, or How the MOA Became Extinct', Philosophical Perspectives 12, pp. 41-54.

Price, Huw 2003: 'Truth as Convenient Friction', Journal of Philosophy 100, pp. 167-90.

Prior, Arthur 1962: 'Changes in Events and Changes in Things', in his Papers on Time and Tense, Oxford: Clarendon Press 1968.

Lewis, David 1986: On the Plurality of Worlds, Oxford: Blackwell.

MacFarlane, John 2003: 'Future Contingents and Relative Truth', Forthcoming in Philosophical Quarterly.

Sainsbury, Mark 1996: 'Crispin Wright: Truth and Objectivity', Philosophy and Phenomenological Research 56, pp. 899-904.

Shapiro, Stewart and Taschek, William W. 1996: 'Intuitionism, Pluralism, and Cognitive Command', Journal of Philosophy 93, pp. 74-88.

Stalnaker, Robert 1978: 'Assertion', in P. Cole (ed.), Syntax and Semantics, vol. 9: Pragmatics, pp. 315-22. Reprinted in Stalnaker 1999.

Stalnaker, Robert 1999: Context and Content, Oxford: Oxford University Press.

Williamson, Timothy 1994: 'Critical Study of Truth and Objectivity', International Journal of Philosophical Studies 2, pp. 130-44.

Wright, Crispin 1992: Truth and Objectivity, Cambridge, Massachusetts: Harvard University Press.

Wright, Crispin 2001: 'On Being in a Quandary', Mind 110, pp. 45-98.

Wright, Crispin 2002: 'Relativism and Classical Logic', in A. O'Hear (ed.), Logic, Thought and Language, Cambridge: Cambridge University Press. 